\title{
Clone libraries and single cell genome amplification reveal extended diversity of uncultivated magnetotactic bacteria from marine and freshwater environments
}

\author{
Sebastian Kolinko, ${ }^{1}$ Gerhard Wanner, ${ }^{1}$ \\ Emanuel Katzmann, ${ }^{1}$ Felizitas Kiemer, ${ }^{1}$ \\ Bernhard M. Fuchs ${ }^{2}$ and Dirk Schüler ${ }^{1 *}$ \\ ${ }^{1}$ Biozentrum der Ludwigs-Maximilians-Universität, \\ Großhaderner Straße 2-4, 82152 Planegg-Martinsried, \\ Germany. \\ ${ }^{2}$ Max Planck Institute for Marine Microbiology, \\ Celsiusstr. 1, 28359 Bremen, Germany.
}

\section{Summary}

Magnetotactic bacteria (MTB), which orient along the earth's magnetic field using magnetosomes, are ubiquitous and abundant in marine and freshwater environments. Previous phylogenetic analysis of diverse MTB has been limited to few cultured species and the most abundant and conspicuous members of natural populations, which were assigned to various lineages of the Proteobacteria, the Nitrospirae phylum as well as the candidate division OP3. However, their known phylogenetic diversity still not matches the large morphological and ultrastructural variability of uncultured MTB found in environmental communities. Here, we used analysis of 16S rRNA gene clone libraries in combination with microsorting and wholegenome amplification to systematically address the entire diversity of uncultured MTB from two different habitats. This approach revealed extensive and novel diversity of MTB within the freshwater and marine sediment samples. In total, single-cell analysis identified eight different phylotypes, which were only partly represented in the clone libraries, and which could be unambiguously assigned to their respective morphotypes. Identified MTB belonged to the Alphaproteobacteria (seven species) and the Nitrospirae phylum (two species). End-sequencing of a small insert library created from WGA-derived DNA of a novel conspicuous magnetotactic vibrio identified

Received 25 July, 2012; revised 7 September, 2012; accepted 21 September, 2012. *For correspondence. E-mail dirk.schueler@ Imu.de; Tel. (+49) 8921807 4514; Fax (+49) 89218074515. genes with highest similarity to two cultivated MTB as well as to other phylogenetic groups. In conclusion, the combination of metagenomic cloning and single cell sorting represents a powerful approach to recover maximum bacterial diversity including lowabundant magnetotactic phylotypes from environmental samples and also provides access to genomic analysis of uncultivated MTB.

\section{Introduction}

Magnetotactic bacteria (MTB) are a diverse group of microorganisms, which are abundant and ubiquitous in chemically stratified aquatic or marine sediments (Flies et al., 2005a; Faivre and Schüler, 2008). Common to all MTB is the presence of intracellular membrane-enclosed ferromagnetic nanocrystals of magnetite $\left(\mathrm{Fe}_{3} \mathrm{O}_{4}\right)$ and/or greigite $\left(\mathrm{Fe}_{3} \mathrm{~S}_{4}\right)$, the magnetosomes (Bazylinski and Frankel, 2004; Jogler and Schüler, 2009; Lefèvre et al., $2011 b)$. The chain-like arrangement of these organelles allows the cells to navigate along the geomagnetic field lines in search for optimum growth conditions within chemical gradients in their stratified aquatic habitats (Frankel et al., 1997; Bazylinski and Frankel, 2004; Faivre and Schüler, 2008).

MTB display a remarkable morphological, ultrastructural and phylogenetic diversity. Analysis of cultivated strains revealed them within the alpha, gamma and delta lineages of the Proteobacteria (Schleifer et al., 1991; Kawaguchi et al., 1995; Lefèvre et al., 2012). In all tested cultivated MTB the genes responsible for magnetosome synthesis were identified within a large and more or less conserved genomic magnetosome island (MAI), which displays variability in different species with respect to gene content and molecular organization (Schübbe et al., 2003; Ullrich et al., 2005; Fukuda et al., 2006; Richter et al., 2007; Lefèvre et al., 2012).

Despite of some recent impressive progress in isolation of novel strains, most MTB still cannot be cultivated in the lab, probably due to their lifestyle adapted to complex chemical gradients in stratified aquatic sediments, making cultivation-independent approaches 
indispensable. Unlike other uncultured bacteria, magnetotactic cells in environmental samples can be directly separated from non-MTB and inorganic matter by taking advantage of their unique magnetically directed motility (Wolfe et al., 1987; Schüler and Bazylinski, 2007). Magnetic enrichment techniques, such as the "capillary racetrack' method and magnetic traps were successfully applied to collect cells for cultivation-independent phylogenetic analysis, which revealed the existence of novel uncultivated MTB belonging to the deep branching Nitrospirae phylum (Spring et al., 1993; Flies et al., 2005b; Lefèvre et al., 2011a). Metagenomic analysis of magnetically collected MTB led to the identification of metabolic genes and large gene clusters homologous to the MAI of cultured MTB (Jogler et al., 2010; Abreu et al., 2011; Lin et al., 2011a).

Whereas most studies of uncultivated MTB were limited to the analysis of highly abundant members of the community, genome amplification from single or few cells of lowabundant morphotypes revealed the existence of novel and extended phylogenetic diversity which had escaped detection by previous mass cloning approaches. For instance, a novel ovoid magnetic bacterium designated as SKK-01 could be assigned to the candidate division OP3, which so far only comprises uncultivated bacteria (Kolinko et al., 2012). The combination of micromanipulation, whole-genome amplification (WGA) and screening of metagenomic libraries identified a magnetosome island in the uncultivated Nitrospirae 'Candidatus Magnetobacterium bavaricum' (Mbav) (Jogler et al., 2011). These studies indicated that the known phylogenetic and genomic diversity still only represents a minor part of the seemingly infinite morphological and ultrastructural variability observed in uncultured MTB from environmental communities.

While previous single-cell studies were limited to individual morphotypes, here we demonstrate that single-cell approaches and WGA can also be applied to the analysis of entire MTB communities. We show that maximum phylogenetic diversity from marine and freshwater habitats was recovered by a combination of single cell techniques and mass cloning strategies. By microsorting, morphotypes could be directly correlated to their corresponding phylotypes. A total of nine phylotypes, some of them putatively representing new genera and species, were assigned to the Alphaproteobacteria class (seven) and the Nitrospirae phylum (two). In addition, we demonstrate the use of small insert libraries from WGA-derived DNA for genomic analysis of single microsorted cells of a novel MTB.

\section{Results}

\section{Diversity analysis by $16 S$ rRNA gene clone libraries}

For diversity analysis, MTB were magnetically collected from single microcosms obtained from two different sampling sites, which were previously found to harbour a variety of diverse MTB: a marine intertidal mudflat sediment from the Wadden sea near Cuxhaven (Cux), (Flies et al., 2005b; Wenter et al., 2009), and a freshwater sediment from Lake Chiemsee (CS) (Spring et al., 1993; Jogler et al., 2010; Kolinko et al., 2012).

Microscopy of hanging drops from Cux enrichments revealed three different magnetic morphotypes present in different relative abundances (Fig. 1, Table 1): An abundant bigger $(\sim 2.5 \mu \mathrm{m})$ coccus named Cux-01 with elongated prismatic magnetosomes contained both electron-dense and opaque granular inclusions, while a smaller $(\sim 1.5 \mu \mathrm{m})$, highly abundant coccus (Cux-02), also with elongated prismatic magnetosomes, had only electron dense granules. A magnetic large vibrio (Cux$03,3.5 \mu \mathrm{m}$ in length) with two characteristic polar electron dense inclusions was present in much lower numbers.

For phylogenetic analysis almost full-length 16S rRNA genes were amplified from magnetic enrichments applying universal eubacterial primers (Lane, 1991) and subcloned. From 50 tested clones, six different sequences were obtained, of which two gave best hits to uncultivated alphaproteo-MTBs from marine sediments of the Chinese sea (Cux-01: 94\% identity to magnetococcus clone XSE-42 (Pan et al., 2008), Cux-02: 96\% identity to magnetococcus clone MRT-97), whereas the other sequences were not similar to known MTB.

Six distinct magnetic morphotypes with different relative abundances (Table 1) were identified in CS samples, which included a small $(\sim 1 \mu \mathrm{m})$ spirillum (CS$01)$, a small $(\sim 1.5 \mu \mathrm{m})(\mathrm{CS}-02)$ and a large $(\sim 2.5 \mu \mathrm{m})$ (CS-04) coccus, two slightly distinct (with and without inclusions) large rods identical to the previously identified Mbav (CS-03) (Jogler et al., 2010; 2011), and a large $(\sim 3.5 \mu \mathrm{m})$ vibrio with polar inclusions (CS-05) (Fig. 2, Table 1). Enrichments were dominated by CS-02 and CS-03 (Mbav), whereas CS-04 and CS-05 were present only in low numbers (Table 1). Although microscopy revealed the virtual absence of any non-MTB from magnetic enrichments, only a minor fraction (3 of 38 ) of subcloned 16S rRNA genes had similarity to known MTB (Table 1). Two sequences gave best hits to uncultivated alphaproteobacterial freshwater magnetic cocci, CS-02 to magnetic coccus clone OUT-51 (99\% identity) (Lin and Pan, 2010) and CS-06 to the magnetic coccus clone 10 (99\% identity) (Lin et al., 2009). A third sequence proved to be identical to Mbav of the Nitrospirae phylum, which was consistently detected in previous analyses of the CS sampling site (Spring et al., 1993; Jogler et al., 2010). All other clones were most similar to various bacterial groups not known to be associated with MTB (data not shown). 

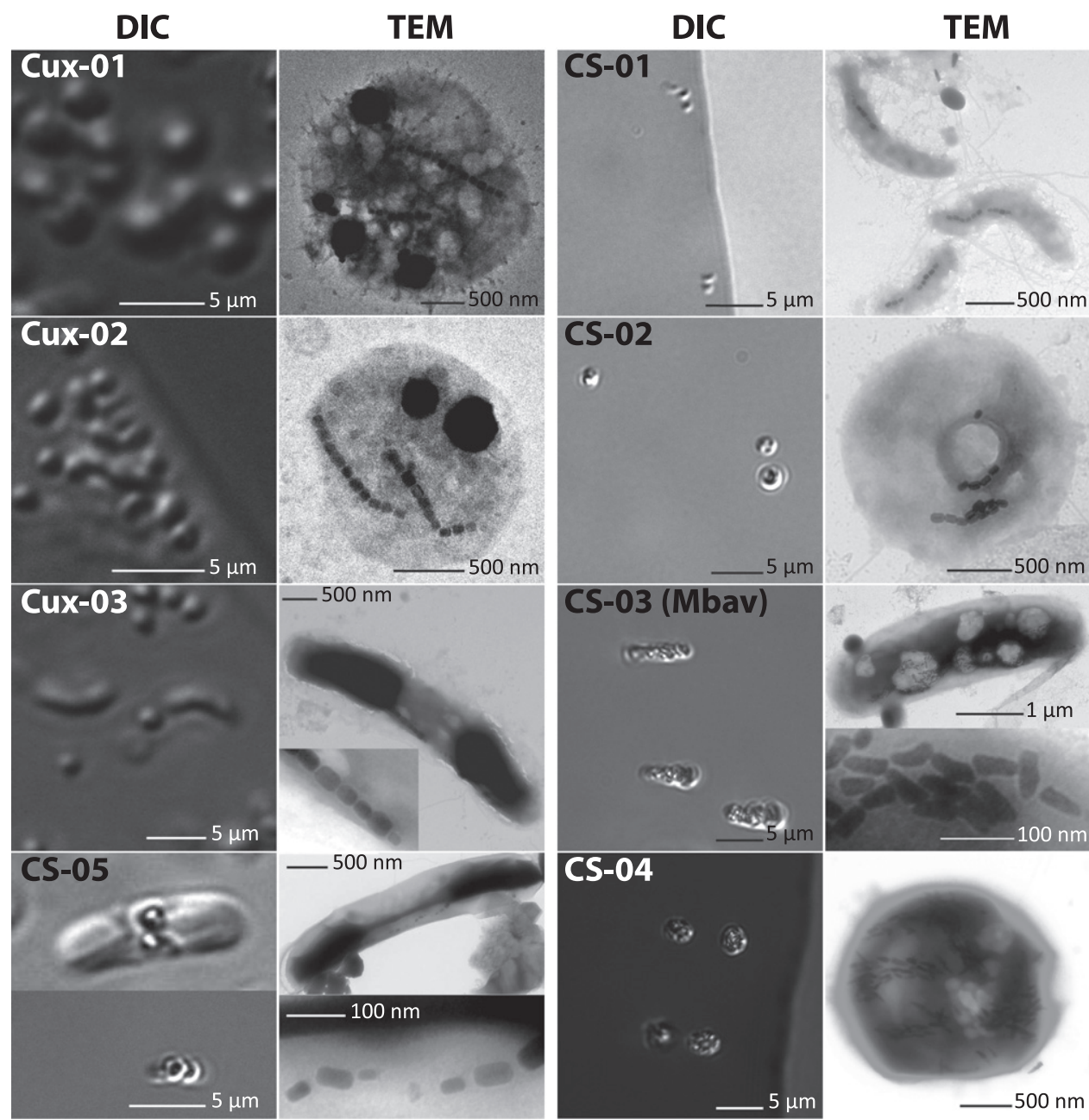

Fig. 1. Differential interference contrast (DIC) and transmission electron micrographs (TEM) of all identified MTB morphologies from freshwater (CS-01-CS-05) and marine (Cux-01-Cux-03) sediments.

\section{Diversity analysis by microsorting}

In previous studies microsorting was used only for large and morphologically conspicuous MTB cells, such as the giant rod Mbav and the big ovoid-shaped SKK-01 from candidate division OP3 (Jogler et al., 2011; Kolinko et al., 2012). However, our magnetic collections also contained very small spirilla-like MTB, which are more difficult to recognize by microscopy and to target by microsorting. To test if this technique could also be reliably applied to these small cells, an artificial mixture consisting of equal cell numbers $\left(\sim 10^{6}\right.$ cells per $\mathrm{ml}$ each) of $E$. coli and spontaneous mutant strain Magnetospirillum gryphiswaldense MSR-1B (Schübbe et al., 2003) was microsorted. As both strains were essentially non-motile and showed no magnetic response, their morphology was the only distinctive characteristic. For each morphotype, DNA from six independent MDA reactions on up to five cells served as a template for subsequent 16S PCR using universal eubac- terial primers. All 16S rRNA gene sequences obtained from MDA reactions only matched their expected origin, and cross-contaminations were never observed, indicating that microsorting can also be applied with high accuracy to small cells.

Next, all different MTB morphotypes from Cux and CS magnetic collections were manually selected under microscopic control and washed in cell-free sample water and $\mathrm{H}_{2} \mathrm{O}$ for at least 10 times to remove contaminants and extracellular DNA prior to MDA. For every morphotype four independent reactions with five cells per reaction were performed. From all reactions, subsequent $16 \mathrm{~S}$ rRNA PCR using amplified DNA as template consistently yielded only one single phylotype, as shown by sequence analysis of 8 clones per clone library revealed and indicating the absence of contaminations (Fig. S1).

Microsorting and WGA of the three MTB morphotypes from Cux resulted in three different 16S rRNA gene sequences. Two of them obtained from the large (Cux-01) 
Table 1. Overview over all MTB identified by magnetic collections and microsorting.

\begin{tabular}{|c|c|c|c|c|c|c|c|c|}
\hline & Organism & Morphology & Abundance & $\begin{array}{l}\text { Identical } \\
\text { clones from } \\
\text { clone library }\end{array}$ & $\begin{array}{l}\text { Sequence } \\
\text { obtained by } \\
\text { microsorting }\end{array}$ & $\begin{array}{l}16 S \\
\text { rDNA } \\
\text { (bp) }\end{array}$ & Best nBLAST hit & $\begin{array}{l}\text { Identity } \\
(\%)\end{array}$ \\
\hline Marine & Cux-01 & & ++ & 12 & + & 1467 & $\begin{array}{l}\text { Uncultured magnetococcus } \\
\text { clone XSE-42 (EF379385) }\end{array}$ & 94 \\
\hline & Cux-02 & & +++ & 21 & + & 1465 & $\begin{array}{l}\text { Uncultured magnetococcus } \\
\text { clone MRT-97 (EF371493) }\end{array}$ & 96 \\
\hline & Cux-03 & & + & 0 & + & 1402 & $\begin{array}{l}\text { Uncultured magnetococcus } \\
\text { clone CF22 (AJ863155) }\end{array}$ & 94 \\
\hline Freshwater & CS-01 & & ++ & 0 & + & 1467 & $\begin{array}{l}\text { Uncultured magnetospirillum } \\
\text { Van25a (HQ222269) }\end{array}$ & 91 \\
\hline & CS-02 & & +++ & 2 & + & 1465 & $\begin{array}{l}\text { Uncultured magnetococcus } \\
\text { clone OTU-51 (GQ468517) }\end{array}$ & 99 \\
\hline & CS-03 & & ++ & 5 & + & 1402 & $\begin{array}{l}\text { Cand. Magnetobacterium } \\
\text { bavaricum (X71838) }\end{array}$ & $\sim 100$ \\
\hline & CS-04 & & + & 0 & + & 1516 & $\begin{array}{l}\text { Cand. Magnetobacterium } \\
\text { mohaviensis LO-1 } \\
\text { (GU979422) }\end{array}$ & 94 \\
\hline & CS-05 & & + & 0 & + & 1414 & $\begin{array}{l}\text { Uncultured magnetococcus } \\
\text { clone TB24 (X81185) }\end{array}$ & 90 \\
\hline & CS-06 & & & 1 & - & 919 & $\begin{array}{l}\text { Uncultured magnetoccocus } \\
\text { clone } 10 \text { (EU786575) }\end{array}$ & 91 \\
\hline
\end{tabular}

The relative abundance of morphotypes in magnetic collections is indicated as follows: +++ highly abundant $(>70 \%),++$ abundant, + rare morphotypes $(<1 \%)$. Bars indicate $1 \mu \mathrm{m}$.

a. Not best hits.

and small coccus (Cux-02) matched the two anonymous MTB-like sequences obtained from the 16S rRNA clone library (99\% cut-off, Table 1). The third sequence, which was not present in the clone library, originated from the large vibrio morphotype with polar electron dense inclusion (Cux-03) (Fig. 1). Cux-03 was assigned to the Alphaproteobacteria and had highest (94\%) identity to an uncultured magnetic coccus clone CF22 from freshwater sediments near Bremen (North Germany) (Flies et al., 2005b).

All five sequences obtained by WGA from microsorted magnetic enrichments from CS gave best hits to known MTB. Two sequences proved to be identical to anonymous clones from the corresponding library. One of them was obtained from the small and highly abundant magnetic coccus CS-02 with highest identity (99\%) to the uncultivated alphaproteobacterial freshwater magnetic coccus clone OTU-51. The other one obtained from the two CS-03 morphotypes (with and without sulfur inclusions) matched the known Mbav sequence as expected.

Three of the 16S rRNA sequences obtained by microsorting and WGA were not present in the corresponding clone library. The sequence amplified from the small spirillum CS-01 had an identity of $91 \%$ to Magnetospirillum sp. enrichment culture clone Van 25 and $89 \%$ identity to M. gryphiswaldense. The coccoid-shaped CS-04 yielded a best hit ( $94 \%$ identity) to 'Candidatus Magnetobacterium mohaviensis' LO-1, which besides Mbav is another MTB previously shown to be affiliated with the Nitrospirae phylum (Lefèvre et al., 2011a) (Fig. 4). The large vibrio CS-05 yielded a best hit to the uncultured 

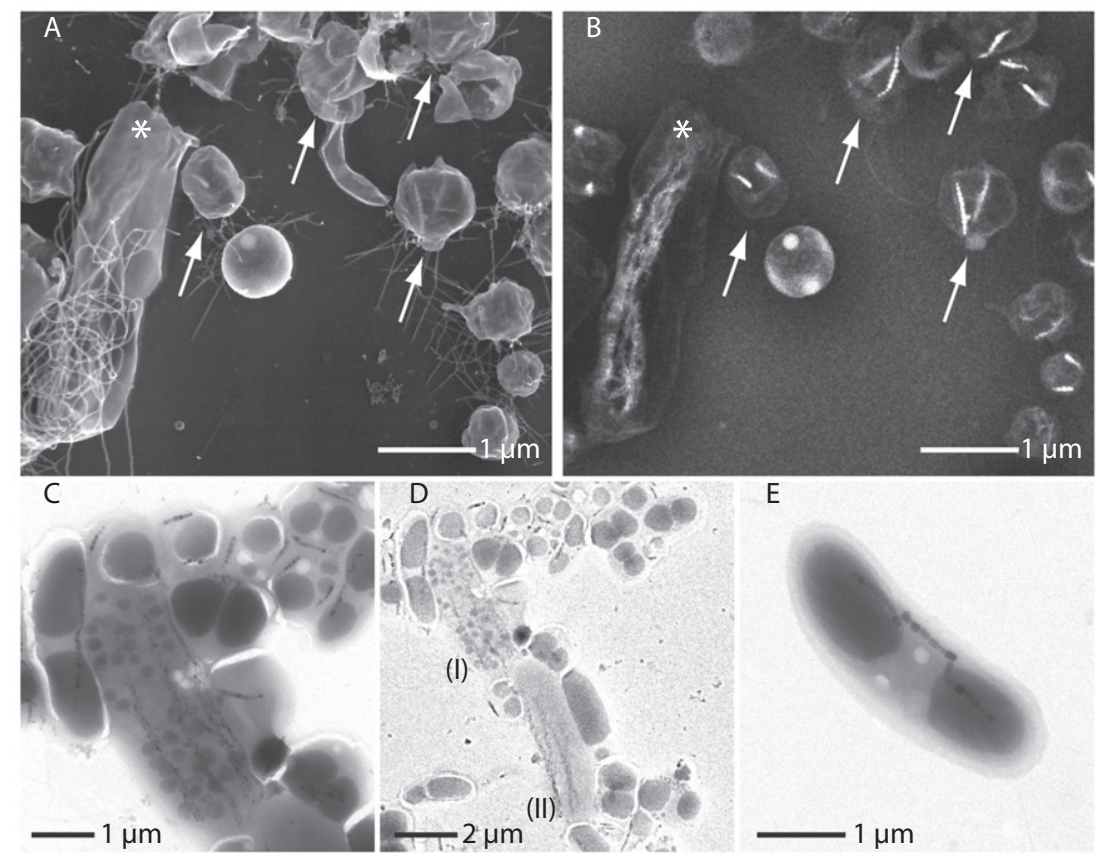

Fig. 2. Electron micrographs of magnetotactic cells from Lake Chiemsee CS sediments. SEM micrographs (accelerating voltage: $15 \mathrm{kV}$ ). Topographic SE image of surface structures of abundant magnetic cocci (arrow) and putative Mbav (asterisk) (A). The back-scattered electron image $(B)$ reveals elongated prismatic magnetosomes in magnetic cocci and bullet-shaped magnetosomes in putative Mbav (B). Transmission electron micrographs of magnetic collections showing (C-D) morphological heterogeneity of Mbav cells; with (I) and without (II) intracellular inclusions (D). Micrograph of a CS-05 cell with two electron dense inclusions and prismatic magnetosomes (E). alphaproteobacterium magnetococcus clone TB24, which was obtained from a freshwater pool (Spring et al., 1995).

\section{Ultrastructural and phylogenetic analysis of selected magnetic cells}

For ultrastructural analysis, selected morphotypes from magnetic collections and those microsorted onto finder grids were further analysed by electron microscopy. CS-03 (Mbav) and CS-04, both belonging to the Nitrospirae phylum, also shared some ultrastructural similarities, such as the presence of bullet-shaped magnetosomes arranged in 3-5 chains as previously described (Fig. 1) (Spring et al., 1993; Lefèvre et al., 2011a). As observed for Mbav, also CS-04 cells displayed some morphological variability with respect to presence of putative sulfur globules (Fig. 2D) (Jogler et al., 2010; Lefèvre et al., 2011a).

In contrast to bipolar monotrichously flagellated cultivated magnetospirilla with cubo-octahedraly magnetite crystals, the small spirillum CS-01 contained elongated magnetosome crystals and had a monopolar bundle of flagella (Fig. 1).

The highly abundant coccus CS-02 contained two chains of elongated prismatic magnetosomes (length $60 \mathrm{~nm}$, width $40 \mathrm{~nm}$ ) (Fig. 3). High-pressure frozen and freeze-substituted cells of CS-02 revealed a typical Gramnegative structure of the cell boundary, displaying an inner and an outer membrane. The outermost rough surface structure might represent a sheath or capsular structure (Fig. 3). Interestingly, the two parallel magnetosome chains were arranged along a putative filamentous structure (approximately $11 \mathrm{~nm}$ in diameter) somehow resembling the cytoskeletal MamK filaments to which in M. gryphiswaldense and other MTB magnetosomes are attached (Jogler et al., 2011; Katzmann et al., 2011) (Fig. 3). Surfaces of the mineral cores became visible in particles where the magnetosome membrane layer was detached upon fractioning, as indicated by the smooth surface of the bare mineral crystal, as compared with presumably intact magnetosomes displaying a granular surface likely to be identical with the surface of the outer leaflet of the magnetosome membrane. Individual magnetosome particles appeared to be attached to the putative filament (Fig. 3 insert). The magnetosome membrane is clearly visible as a hollow membrane-like structure after apparent loss of magnetite cores during freeze fracturing (Fig. 3A).

Despite of their different phylogenetic affiliation, geographical origin and ecology, the two vibrioid morphotypes Cux-03 (marine) and CS-05 (freshwater) shared an intriguing morphological similarity. Both strains were about $3.5 \mu \mathrm{m}$ in length and had one chain of elongated prismatic magnetosome crystals (115 $\pm 18 \mathrm{~nm}$ in length) that traverses the cell at its inner curvature. Magnetosome crystals consist of an iron oxide (likely magnetite), as indicated by coinciding signals for iron and oxygen, but not sulfur in energy-dispersive X-ray spectroscopy (EDX) (Fig. 3). In addition, they both displayed characteristic large electron dense inclusions at their poles (Fig. 3), which in CS-05 yielded colocalized signals for phosphorus and oxygen by EDX, identifying them as putative storage granules of phosphate (Silva et al., 2008). 

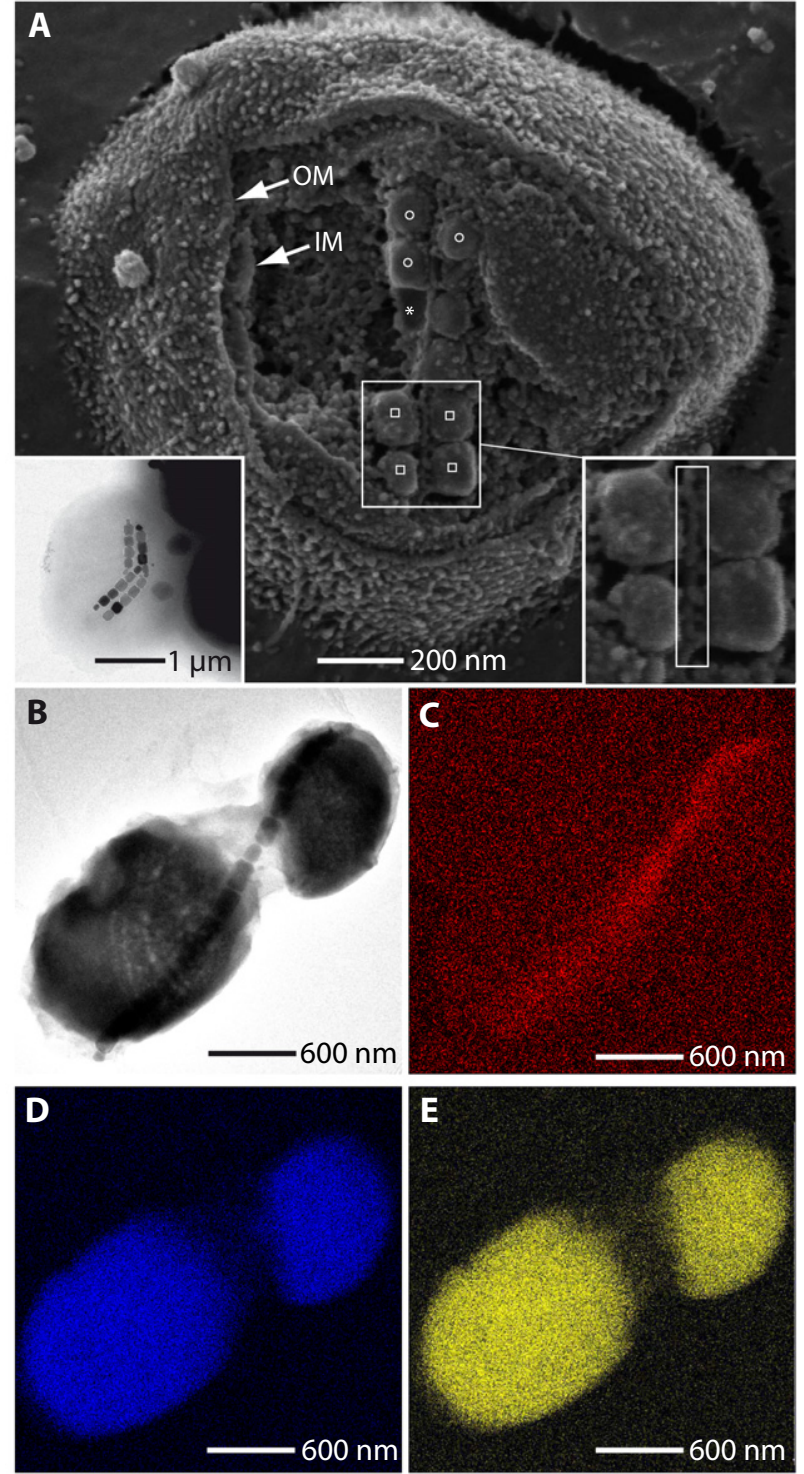

Fig. 3. Ultrastructural analysis.

A. SEM micrograph of a fractured frozen hydrated CS-02 cell. The cell has a Gram-negative cell wall with an outer (OM) and inner membrane (IM). Magnetosome particles displaying either the rough surface of the outer magnetosome membrane leaflet $(\square)$ or the smooth surface of the bare mineral core $(O)$ are indicated.

Magnetosomes form a chain arranged along a putative cytoskeletal filament (rectangular area in inset).

B-E. Ultrastructure of morphotype CS-05. TEM micrograph shows a magnetosome chain traversing the cell with its polar electron dense inclusions (B). Energy dispersive X-ray spectroscopy (EDX) revealed $\mathrm{Fe}$ content within magnetosomes highlighting the magnetosome chain traversing the cell $(C)$ and oxygen and phosphor rich components of the cell, which coincide with its polar electron dense inclusions (D and $E$ ).

\section{Genomic analysis of microsorted CS-05}

Despite their morphological resemblance, CS-05 and Cux-03 share an identity of only 90\% in their 16S rRNA genes and affiliate with different branches within the
Alphaproteobacteria (Fig. 4). Similar morphotypes were reported previously from magnetic collections from various environments, but their phylogenetic assignment was not identified (Vali and Kirschvink, 1991; Schüler, 1994; Spring and Schleifer, 1995; Flies et al., 2005b), and nothing is known about the genetics and ecophysiology of these characteristic MTBs. To obtain first genomic information, double-amplified DNA from two subsequent MDA reactions on microsorted CS-05 cells was used for the generation of a small insert library (SIL) as described previously (Simon and Daniel, 2010). Endsequencing of all 27 clones (average insert size $\sim 2 \mathrm{~kb}$, read length $\sim 800 \mathrm{bp}$ ) revealed hits to 38 different genes (Table 2). Seventy-five per cent showed highest similarity to proteobacterial genes, while the others yielded hits to Archaea $(10 \%)$, Firmicutes (3\%), Cyanobacteria (3\%), Planctomycetales $(1.5 \%)$, Chlorobiaceae $(1.5 \%)$ and unknown bacteria (6\%). Notably, 13 genes generated hits to the cultivated MTB Magnetococcus MC-1 and Desulfovibrio magneticus RS-1.

In addition to eight hypothetical genes, 30 genes have predicted functions, with eight involved in signal transduction, six related to the electron transport chain, whereas other genes are involved in DNA organization and repair $(8 \%)$, protein biosynthesis $(8 \%)$, metal ion translocation $(5 \%)$, lipid and cell wall biosynthesis $(5 \%)$ and regulation $(2.5 \%)$ (Table 2). As expected from the small sample size, which is likely to represent less than $1 \%$ coverage, if assuming a characteristic genome size of about $5 \mathrm{Mb}$, no putative mam genes involved in magnetosome formation were identified.

\section{Discussion}

So far phylogenetic analysis of uncultivated MTB was mostly achieved by $16 S$ rRNA PCR amplification on DNA from complex multispecies magnetic enrichments followed by mass cloning and screening of libraries (Ludwig and Schleifer, 1994; Amann et al., 2006; Postec et al., 2012). This technique relies on high cell numbers and detects only highly abundant MTB, while low abundant representatives are likely to be missed (Amann et al., 2006). In addition, obtained sequences are anonymous, and the correlation of phylo- to morphotypes requires FISH and fluorescence microscopy. Recently, single cell techniques facilitated the amplification and de novo assembly of whole genomes from uncultivated marine, freshwater and symbiotic bacteria, allowing to link morphological and genomic information (Rodrigue et al., 2009; Woyke et al., 2010; Chitsaz et al., 2011) Microsorting and WGA were also applied for the phylogenetic and ultrastructural analysis of large and morphologically conspicuous, abundant MTB from Nitrospirae (Jogler et al., 2010; 2011), but also led to the discovery of novel 


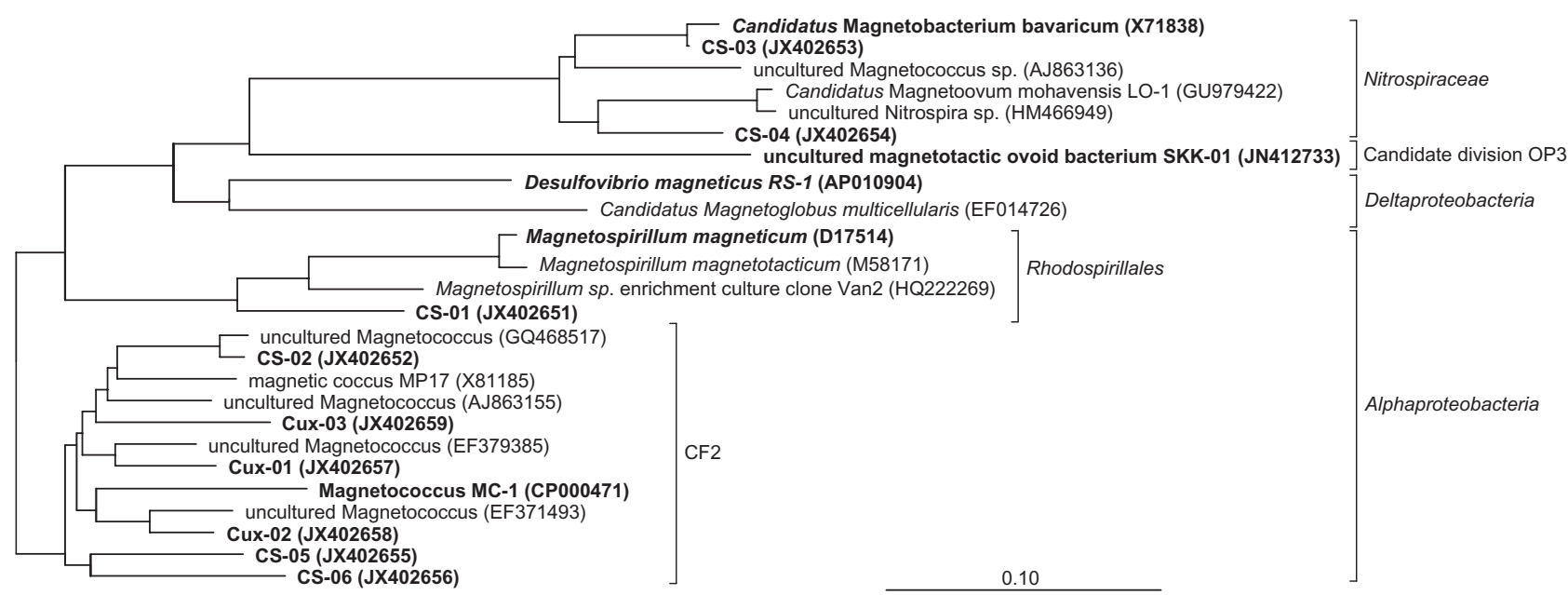

Fig. 4. Phylogenetic tree of $16 S$ rRNA gene sequences retrieved from magnetic collections from Lake Chiemsee (CS) and Cuxhaven (Cux) by mass cloning and microsorting showing their phylogenetic affiliation.

low-abundant MTB (Kolinko et al., 2012). Here, we used a combination of mass cloning of 16S rRNA genes and microsorting followed by WGA to target all MTB species present in magnetic collections from two environmental samples. We demonstrated that microsorting is not confined to large and morphologically conspicuous cells, but can also reliably be applied to other members of MTB communities such as small spirilla and cocci, as well as to high and low abundant MTB.

All three morphotypes present in the marine sample (Cux) could be linked to three different alphaproteobacterial species. Two of them were also represented in the clone library, whereas the least abundant morphotype (Cux-03) was missing. In the freshwater sample (CS) five of six MTB phylotypes were identified by single cell sorting, whereas clone library revealed only two of the most abundant MTB, but in addition identified one anonymous phylotype that was missed by single cell sorting. In conclusion, single cell sorting is more effective in the detection of low abundant MTB, whereas the combination of the two methods is likely to reveal maximum diversity.

It should be noted, however, that the identified species may not necessarily represent the entire MTB diversity present in the environment, because magnetic collections under our conditions are likely biased for aerotolerant and highly motile MTB. Second, microcosms stored in the lab are known to change in MTB community composition (Flies et al., 2005a), as illustrated by the absence of MMP and SKK-01-like bacteria, which were previously observed in the same marine and freshwater sampling sites respectively (Wenter et al., 2009; Kolinko et al., 2012). Thus, the somewhat higher diversity observed in the freshwater sample (6 versus 4) phylotypes in the marine sample might rather result from the lower stability of marine samples, as marine and freshwater phylotypes are about equally represented (122 versus 125 16S rRNA sequences) in the MTB databases (http://database. biomnsl.com/index.html) (Lin et al., 2011b). Performing similar experiments on environmental samples in situ and under less selective conditions (e.g. by performing all steps in the absence of oxygen) is likely to reveal considerably higher diversity from various environments.

In total we identified nine different phylotypes. Whereas two of them (CS-02 and CS-03) are relatively closely related to previously identified MTB, six (Cux-01, Cux-02, Cux-03, CS-01, CS-04 and CS-05) displayed sequence divergence well beyond the species level (<97\% identity). Sequences of CS-01, CS-05 and CS-06 show very low identities to known MTB, and thus might each represent a new genus within the Alphaproteobacteria (Fig. 4).

Among the novel and more divergent MTB is the ovoidshaped CS-04 affiliated with the Nitrospirae phylum. Although its morphology is strongly resembling that of the other Nitrospirae MTB LO-1 and MWB-1, which also exhibit an ovoid cell shape and bullet-shaped magnetosomes arranged in bundles of chains, CS-04 is not very closely related to them at the 16S rRNA level (94\% identity to LO-1, 91\% to MWB-1) (Lefèvre et al., 2011a; Lin et al., 2012). This suggests that the phylogenetic diversity within this group is higher than initially assumed and further indicates a wider geographic distribution of ovoid Nitrospirae MTB.

Another example for novel diversity is represented by the species Cux-03 and CS-05. Despite their different geographic origin and ecology (marine versus freshwater) both strains share considerable morphological similarity. Similar morphotypes were repeatedly reported but not identified in previous studies (Vali and Kirschvink, 1991; Schüler, 1994; Spring et al., 1995). The closest 16S rRNA relatives of Cux-03 and CS-05 are two 
Table 2. Results of BLAST analysis of protein fragments encoded by endsequences against the NCBI database.

\begin{tabular}{|c|c|c|c|c|c|}
\hline Clone & Best hit & Coverage $(\%)$ & Identity (\%) & E-value & Accession \\
\hline \multirow[t]{2}{*}{ A02 } & Cytochrome C class I [MC-1] & 75 & 52 & $6.0 \mathrm{E}-50$ & YP866892 \\
\hline & SMC domain containing protein [Syntroothermus] & 48 & 53 & 5.0E-05 & YP00370187 \\
\hline \multirow[t]{2}{*}{ A03 } & Cytochrome C monodihaem variants family [Burkholderia] & 30 & 48 & 1.0E-22 & ZP09753705 \\
\hline & Transposase IS66 [unc. Bacterium] & & & $2.0 \mathrm{E}-87$ & CAX837781 \\
\hline \multirow[t]{4}{*}{ A04 } & Cation diffusion facilator family transport [Halorubrum] & 47 & 33 & $9.0 \mathrm{E}-12$ & YP00256586 \\
\hline & Cobalt/zinc/cadmium efflux pump [Thermococcus] & 35 & 33 & 2.0E-20 & YP00476292 \\
\hline & Similar to type IV pillus assembly PilZ [unc. Bacterium] & 18 & 57 & $7.0 \mathrm{E}-46$ & CAX84240 \\
\hline & PAS/PAC sensor hybrid histidine kinase [MC-1] & 59 & 51 & 3.0E-49 & YP866289 \\
\hline A05 & Hypothetical protein Neut_222 [Neutrosomonas] & 44 & 47 & 2.0E-51 & YP748404 \\
\hline \multirow[t]{2}{*}{ A08 } & Pyruvate phosphate dikinase [MC-1] & 99 & 60 & $1.0 \mathrm{E}-125$ & YP866101 \\
\hline & Sensor histidine kinase $[\mathrm{RS}-1]^{\mathrm{a}}$ & 37 & 27 & 1.0E-04 & YP00295553 \\
\hline A09 & Phosphoesterase PA-phosphatase related [Lutiella] & 45 & 28 & 0.22 & ZP03633678 \\
\hline \multirow[t]{2}{*}{ A10 } & Response regulator modulated CheB methylesterase [Cyanothece] & 86 & 49 & 1.0E-38 & YP00388954 \\
\hline & Response regulator modulated CheB methylesterase $[\mathrm{MC}-1]^{\mathrm{a}}$ & 86 & 48 & 1.0E-38 & YP865749 \\
\hline A11 & Unnamed protein product [Synechococcus] & 89 & 46 & 7.0E-09 & YP400828 \\
\hline \multirow[t]{2}{*}{ A12 } & Hypothetical protein ThithDRAFT [Thioalkalivibrio] & 95 & 42 & 1.0E-67 & ZP08929740 \\
\hline & Hypothetical protein ThithDRAFT 16_16 [Thioalkalivibrio] & 34 & 45 & 1.0E-21 & ZP08929741 \\
\hline \multirow[t]{2}{*}{ B01 } & DNA repair ATPase-like protein [Acidaminococcus] & 66 & 69 & 2.0E-07 & YP00339991 \\
\hline & Response regulator receiver [MC-1] & 35 & 44 & 1.0E-21 & YP867106 \\
\hline B02 & Hypothetical protein VCO395_A2678 [Vibrio cholerae] & 96 & 46 & 2.0E-39 & YP001218556 \\
\hline B04 & Putative hydrolase [Pseudomonas] & 35 & 70 & 1.0E-37 & EGMI16298 \\
\hline B08 & SMC domain protein [Singulisphaera] & 47 & 28 & 2.0E-09 & ZP09568834 \\
\hline B09 & Aspartate carbamoyltransferase [MC-1] & 52 & 71 & 8.0E-90 & YP864038 \\
\hline \multirow[t]{3}{*}{ B11 } & NADH dehydrogenase [Chlorobium] & 49 & 78 & $2.0 \mathrm{E}-88$ & YP00195891 \\
\hline & Hypothetical protein Neut_222 [Nitrosomonas] & 44 & 47 & $2.0 \mathrm{E}-51$ & YP748404 \\
\hline & Multi-sensor hybrid histidine kinase [MC-1] ${ }^{\mathrm{a}}$ & 79 & 26 & $6.0 \mathrm{E}-24$ & YP866850 \\
\hline \multirow[t]{2}{*}{$\mathrm{C02}$} & Putative serin/threonin proter phosphatase-like protein [MC-1] & 29 & 42 & $2.0 \mathrm{E}-21$ & YP866040 \\
\hline & Putative GAF sensor protein & 32 & 35 & 1.0E-09 & YP864160 \\
\hline \multirow[t]{2}{*}{$\mathrm{CO4}$} & 30s ribosomal protein S5 [MC-1] & 45 & 77 & 1.0E-64 & YP864789 \\
\hline & rp/P gene product $[\mathrm{MC}-1]^{\mathrm{a}}$ & 39 & 80 & 1.0E-68 & YP864779 \\
\hline $\mathrm{C05}$ & Unnamed protein product [Desulfovibrio africanus] & 97 & 49 & 1.0E-37 & YP00505256 \\
\hline \multirow[t]{2}{*}{$\mathrm{CO6}$} & $\mathrm{ABC}$ transporter $[\mathrm{MC}-1]$ & 46 & 46 & 1.0E-26 & YP866032 \\
\hline & Molybdopterin oxidoreductase & 33 & 44 & 1.0E-18 & YP865545 \\
\hline \multirow[t]{2}{*}{$\mathrm{C} 07$} & Two-component hybrid sensor and regulator $[\mathrm{RS}-1]^{\mathrm{a}}$ & 32 & 33 & 2.0E-27 & YP00295229 \\
\hline & Molybdopterin oxidoreductase & 93 & 61 & 1.0E-75 & YP865545 \\
\hline $\operatorname{Co8}$ & Hypothetical protein [Nitrosococcus] & 26 & 55 & 1.0E-22 & YP00376112 \\
\hline $\operatorname{cog}$ & tRNA delta(2)-isopentenylpyrophosphate transferase [Pelobacter] & 63 & 55 & 1.0E-68 & YP358505 \\
\hline \multirow[t]{2}{*}{$\mathrm{C} 10$} & Cobalt/zinc/cadmium efflux pump [Thermococcus] & 35 & 33 & 2.0E-20 & YP00476292 \\
\hline & Similar to type IV pillus assembly PilZ [unc. Bacterium] & 18 & 57 & $7.0 \mathrm{E}-46$ & CAX84240 \\
\hline D03 & O-antigen polymerase [MC-1] & 20 & 45 & 1.0E-07 & YP864509 \\
\hline \multirow[t]{2}{*}{ D04 } & Sensory box protein/sigma-54 [unc. Bacterium] & 79 & 69 & $5.0 \mathrm{E}-125$ & CAX84064 \\
\hline & ATP-dependent protease LON [RS-1 $]^{\mathrm{a}}$ & 26 & 33 & $1.0 \mathrm{E}-08$ & YP00295245 \\
\hline \multirow[t]{3}{*}{ D07 } & Hypothetical protein XVE_4190 [Xanthomonas] & 95 & 63 & 1.0E-86 & ZP08180168 \\
\hline & Hypothetical protein DMR-36100 [RS-1] ${ }^{\mathrm{a}}$ & 34 & 46 & 1.0E-25 & YP00295498 \\
\hline & Hypothetical protein Mmc_2715 [MC-1] ${ }^{\mathrm{a}}$ & 95 & 63 & 2.0E-23 & YP866614 \\
\hline D09 & Rhodanese-like sulfurtransferase PspE [Cupriavidus] & 29 & 96 & $5.0 \mathrm{E}-68$ & ZP09627450 \\
\hline
\end{tabular}

a. Not best hits.

different uncultured magnetic cocci, and despite of their morphological resemblance $\mathrm{Cux}-03$ and CS-05 share only relatively low $16 \mathrm{~S}$ identity with each other (90\%). This provides a further example that morphologically similar MTB are not necessarily closely related, as it was also shown before for the phylogenetically divergent uncultivated MTB LO-1 and SKK-01 (Lefèvre et al., 2011a; Kolinko et al., 2012). Vice versa, CS-05 remarkably is the first rod or vibrio-shaped species found to branch within the so-called CF2 group, which so far was thought to comprise only coccoid MTB. However, unas- signed 16S rDNA sequences (TB24) with 90\% identity to CS-05 were previously reported from magnetic collections from freshwater that also contained vibrioid MTB (Spring et al., 1995), suggesting that related species are more abundant in various environments.

The most characteristic feature shared by Cux-03 and CS-05 is the presence of large inclusions identified as granules of phosphate, which in some cells were found to occupy up to two-thirds of the cell volume. As in other bacteria, polyphosphate granules may serve as energy source, or as phosphate or chelated metal storage 
(Achbergerová and Nahalka, 2011), a similar function in MTB can be hypothesized. We also were able to obtain first genomic information of CS-05 by end-sequencing of 27 clones of a DNA library generated from the amplified genomes of few cells. Future analysis of near complete genome data will likely generate insights into the putative metabolism of this organism. In addition, it demonstrates that single cell analysis is not limited to ultrastructure and conserved phylogenetic marker genes of uncultured MTB, but in future studies can be applied for the complete genomic analysis of, in theory, all microscopically detectable members of environmental MTB communities.

\section{Experimental procedures}

\section{Bacterial strains, media and growth conditions}

Escherichia coli $\mathrm{DH} 5 \alpha$ strains were cultivated in liquid lysogeny broth at $37^{\circ} \mathrm{C}$ under aerobic conditions. Liquid cultures of Magnetospirillum MSR-1B were cultivated in FSM medium at $30^{\circ} \mathrm{C}$ under aerobic conditions as described previously (Schübbe et al., 2003).

\section{Sediment sampling and magnetic collections}

Freshwater sediments from Lake Chiemsee (CS, Germany, Bavaria) $\left(47^{\circ} 51^{\prime} 08^{\prime \prime} \mathrm{N}, 12^{\circ} 24^{\prime} 00^{\prime \prime} \mathrm{E}\right)$ were collected in July 2010 from $10-20 \mathrm{~m}$ depth applying a bottom sampler. Aquaria were filled with 18-25 I of sediment slurry and covered with the same volume of sample water. To allow stratification, microcosms were stored at room temperature for several months. The sediment colour in the oxic sediment layers $(\sim 4 \mathrm{~mm})$ was brownish, and then greyish down to $10 \mathrm{~mm}$ depth and below changed to black. Marine sediment cores were collected at low tide from an intertidal flat from the German Wadden see near Cuxhaven (Cux), Germany $\left(53^{\circ} 53^{\prime} 32^{\prime \prime} \mathrm{N}, 8^{\circ} 40^{\prime} 45^{\prime \prime} \mathrm{E}\right)$ in April 2010 . Stratified sandy sediments were overlaid with sea water and stored at RT in the dark without disturbing stratification. The sediment colour was brownish in the upper $5 \mathrm{~mm}$ of oxic sediment, then greyish down to $3-4 \mathrm{~cm}$ depth and below changed to black due to a high FeS content.

Magnetic enrichments from the freshwater sample (CS) were performed as previously described (Jogler et al., 2009). In brief, MTB were magnetically collected from mud slurries containing $10 \mathrm{ml}$ of sediment cores mixed with $30 \mathrm{ml}$ of sample water. Magnetic collections were transferred into a magnetic trap for further enrichment. Marine MTB were enriched by applying the south pole of a magnet $2 \mathrm{~cm}$ above the sediment for $20 \mathrm{~min}$. Enriched cells were directly used for downstream analysis.

\section{Micromanipulation and WGA}

Micromanipulation and WGA of single cells was performed as previously described (Kolinko et al., 2012). In brief, single cells were microsorted and washed under strict microscopic control to remove contaminations and extracellular DNA and transferred onto an AmpliGrid AG480F (Beckman Coulter, Krefeld, Germany) for subsequent WGA.

\section{Determination of $16 S$ rRNA gene sequences and phylogenetic analysis}

The 16S rRNA genes were amplified using universal eubacteria-specific primers $27 \mathrm{~F}$ and 1492R (Lane, 1991) and $50 \mathrm{ng}$ of WGA derived DNA or a magnetic enrichment $\left(\sim 10^{6}\right.$ cells) served as template. PCR products were cloned into pJET1.2/blunt Cloning Vector (Fermentas, Waltham, MA, USA) and sequenced with an $\mathrm{ABI}$ system according to the instructions of the manufacturer. Alignment of gene sequences was performed with the AlignX algorithm of the Vector NTI software version 11.0 (Invitrogen, Carlsbad, CA, USA). No chimerical sequences were identified using the Bellerophon algorithm (Huber et al., 2004).

16S rRNA gene sequences from WGA experiments were analysed using the ARB software package version 5.2 (Ludwig et al., 2004) and the SILVA SSU Ref database release 108 from April 2011 (Pruesse et al., 2007). Briefly, nearly full-length $16 \mathrm{~S}$ rRNA gene sequences were automatically aligned using the SINA aligner (Pruesse et al., 2012) and manual refinement was carried out taking into account the secondary structure information of the native rRNA. For initial classification, MTB sequences were added to the corresponding guide trees of the SSU SILVA data set using the ARB parsimony tool. Based on this information, final tree reconstruction was performed with selected reference sequences and a larger number of their close relatives to stabilize tree topology. Reference sequences of MTB were selected from the DMTB database (http://database. biomnsl.com/). In total, 1020 sequences of the SSU data set were used to reconstruct a neighbour joining tree (ARB neighbour joining tool). Sequences described in this study can also be downloaded from the databases of the INSDC, comprising DDBJ, EMBL and GenBank.

\section{Construction of a small insert partial genomic library}

A small insert library of amplified genomic DNA was constructed similar as described previously (Simon and Daniel, 2010). In brief, WGA-derived DNA from CS-05 cells was amplified by a second round of WGA, enzymatically debranched and size selected for subcloning into pJET1.2/ blunt Cloning Vector (Fermentas, Waltham, MA, USA) following the specifications of the manufacturer. All clones were prepared for end-sequencing applying specific pJet primers and sequenced with an $\mathrm{ABI}$ system according to the instructions of the manufacturer. Sequences were analysed against the NCBI database applying the xBLAST algorithm (Altschul et al., 1997).

\section{Light and electron microscopy}

Magnetic collections were examined by hanging drop assay (Frankel et al., 1997; Schüler and Bazylinski, 2007) using a SM-LUX (Leitz, Wetzlar, Germany) phase-contrast microscope. For ultrastructural analysis magnetically responsive cells were transferred to grids. For TEM of CS-05, single cells were sorted onto finder grids under microscopic control. 
Transmission electron microscopy (TEM) was performed with a FEI Tecnai F20 (200 kV) TEM equipped with an Eagle charge-coupled-device camera (4096 by 4096 pixels). Cells were adsorbed on carbon-coated copper grids (Plano, Wetzlar, Germany). Images were acquired using EMMenue 4.0 and FEI software. For structural analysis, sorted cells were examined with a Zeiss AURIGA ${ }^{\circledR}$ high-resolution fieldemission scanning electron microscope operated at $25 \mathrm{keV}$. SE and BSE images were simultaneously recorded with the chamber SE and QBSD detectors. For energy-dispersive X-ray (EDX) analysis (point analysis and EDX mapping) a Bruker QUANTAX double detector system $\left(2 \times 30 \mathrm{~mm}^{2}\right.$ $\mathrm{XFlash}^{\odot}$ ) was used at a working distance of $6 \mathrm{~mm}$ and $25 \mathrm{kV}$.

For high-pressure freezing, aluminium platelets were filled with concentrated cell suspensions and the cells immobilized by high-pressure freezing (Leica HPM100). For cryoscanning electron microscopy high-pressure frozen samples were fractured with a Leica EM MED020, sublimated for 1-2 min a $-95^{\circ} \mathrm{C}$ and coated with $3 \mathrm{~nm}$ tungsten, transferred to the scanning electron microscope and examined at $1 \mathrm{kV}$.

\section{Acknowledgements}

This work was supported by Deutsche Forschungsgemeinschaft (grant DFG Schu1080/9-1 and 11-1 to D.S.). We thank Silvia Dobler for excellent technical assistance.

\section{References}

Abreu, F., Cantão, M.E., Nicolás, M.F., Barcellos, F.G., Morillo, V., Almeida, L.G., et al. (2011) Common ancestry of iron oxide- and iron-sulfide-based biomineralization in magnetotactic bacteria. ISME J 5: 1634-1640.

Achbergerová, L., and Nahalka, J. (2011) Polyphosphate-an ancient energy source and active metabolic regulator. Microb Cell Fact 10: 63.

Altschul, S.F., Madden, T.L., Schaffer, A.A., Zhang, J., Zhang, Z., Miller, W., and Lipman, D.J. (1997) Gapped BLAST and PSI-BLAST: a new generation of protein database search programs. Nucleic Acids Res 25: 3389-3402.

Amann, R., Peplies, J., and Schüler, D. (2006) Diversity and Taxonomy of Magnetotactic Bacteria. In Magnetoreception and Magnetosomes in Bacteria. Schüler, D. (ed.). Heidelberg: Springer-Verlag, pp. 25-36.

Bazylinski, D.A., and Frankel, R.B. (2004) Magnetosome formation in prokaryotes. Nat Rev Microbiol 2: 217230.

Chitsaz, H., Yee-Greenbaum, J.L., Tesler, G., Lombardo, M.J., Dupont, C.L., Badger, J.H., et al. (2011) Efficient de novo assembly of single-cell bacterial genomes from shortread data sets. Nat Biotech 29: 915-921.

Faivre, D., and Schüler, D. (2008) Magnetotactic bacteria and magnetosomes. Chem Rev 108: 4875-4898.

Flies, C.B., Jonkers, H.M., de Beer, D., Bosselmann, K., Böttcher, M.E., and Schüler, D. (2005a) Diversity and vertical distribution of magnetotactic bacteria along chemical gradients in freshwater microcosms. FEMS Microbiol Ecol 52: 185-195.
Flies, C.B., Peplies, J., and Schüler, D. (2005b) Combined approach for characterization of uncultivated magnetotactic bacteria from various aquatic environments. Appl Environ Microbiol 71: 2723-2731.

Frankel, R.B., Bazylinski, D.A., Johnson, M.S., and Taylor, B.L. (1997) Magneto-aerotaxis in marine coccoid bacteria. Biophys J 73: 994-1000.

Fukuda, Y., Okamura, Y., Takeyama, H., and Matsunaga, T. (2006) Dynamic analysis of a genomic island in Magnetospirillum sp. strain AMB-1 reveals how magnetosome synthesis developed. FEBS Lett 580: 801-812.

Huber, T., Faulkner, G., and Hugenholtz, P. (2004) Bellerophon: a program to detect chimeric sequences in multiple sequence alignments. Bioinformatics 20: 2317-2319.

Jogler, C., and Schüler, D. (2009) Genomics, genetics, and cell biology of magnetosome formation. Annu Rev Microbiol 63: 501-521.

Jogler, C., Lin, W., Meyerdierks, A., Kube, M., Katzmann, E., Flies, C., et al. (2009) Toward cloning of the magnetotactic metagenome: identification of magnetosome island gene clusters in uncultivated magnetotactic bacteria from different aquatic sediments. Appl Environ Microbiol 75: 39723979.

Jogler, C., Niebler, M., Lin, W., Kube, M., Wanner, G., Kolinko, S., et al. (2010) Cultivation-independent characterization of 'Candidatus Magnetobacterium bavaricum' via ultrastructural, geochemical, ecological and metagenomic methods. Environ Microbiol 12: 2466-2478.

Jogler, C., Wanner, G., Kolinko, S., Niebler, M., Amann, R., Petersen, N., et al. (2011) Conservation of proteobacterial magnetosome genes and structures in an uncultivated member of the deep-branching Nitrospirae phylum. Proc Natl Acad Sci USA 108: 1134-1139.

Katzmann, E., Müller, F.D., Lang, C., Messerer, M., Winklhofer, M., Plitzko, J.M., and Schüler, D. (2011) Magnetosome chains are recruited to cellular division sites and split by asymmetric septation. Mol Microbiol 82: 1316-1329.

Kawaguchi, R., Burgess, J.G., Sakaguchi, T., Takeyama, H., Thornhill, R.H., and Matsunaga, T. (1995) Phylogenetic analysis of a novel sulfate-reducing magnetic bacterium, RS-1, demonstrates its membership of the deltaProteobacteria. FEMS Microbiol Lett 126: 277-282.

Kolinko, S., Jogler, C., Katzmann, E., Wanner, G., Peplies, J., and Schüler, D. (2012) Single-cell analysis reveals a novel uncultivated magnetotactic bacterium within the candidate division OP3. Environ Microbiol 14: 1709-1721.

Lane, D.J. (1991) 16S/23S sequencing. In Nucleic Acid Techniques in Bacterial Systematics. Stackebrandt, E., and Goodfellow, M. (eds). Chichester, UK: Wiley, pp. 115-175.

Lefèvre, C.T., Frankel, R.B., Abreu, F., Lins, U., and Bazylinski, D.A. (2011a) Culture-independent characterization of a novel, uncultivated magnetotactic member of the Nitrospirae phylum. Environ Microbiol 13: 538-549.

Lefèvre, C.T., Menguy, N., Abreu, F., Lins, U., Posfai, M., Prozorov, T., et al. (2011b) A cultured greigite-producing magnetotactic bacterium in a novel group of sulfatereducing bacteria. Science 334: 1720-1723.

Lefèvre, C.T., Viloria, N., Schmidt, M.L., Posfai, M., Frankel, R.B., and Bazylinski, D.A. (2012) Novel magnetiteproducing magnetotactic bacteria belonging to the Gammaproteobacteria. ISME J 6: 440-450. 
Lin, W., and Pan, Y. (2010) Temporal variation of magnetotactic bacterial communities in two freshwater sediment microcosms. FEMS Microbiol Lett 302: 85-92.

Lin, W., Li, J., Schüler, D., Jogler, C., and Pan, Y. (2009) Diversity analysis of magnetotactic bacteria in Lake Miyun, northern China, by restriction fragment length polymorphism. Syst Appl Microbiol 32: 342-350.

Lin, W., Jogler, C., Schüler, D., and Pan, Y. (2011a) Metagenomic analysis reveals unexpected subgenomic diversity of magnetotactic bacteria within the phylum Nitrospirae. Appl Environ Microbiol 77: 323-326.

Lin, W., Li, B., and Pan, Y. (2011b) DMTB: a comprehensive online resource of $16 \mathrm{~S}$ rRNA genes, ecological metadata, oligonucleotides, and magnetic properties of magnetotactic bacteria. Chin Sci Bull 56: 476-478.

Lin, W., Li, J., and Pan, Y. (2012) Newly isolated but uncultivated magnetotactic bacterium of the phylum Nitrospirae from Beijing, China. Appl Environ Microbiol 78: 668-675.

Ludwig, W., and Schleifer, K.H. (1994) Bacterial phylogeny based on 165 and $23 S$ rRNA sequence analysis. FEMS Microbiol Rev 15: 155-173.

Ludwig, W., Strunk, O., Westram, R., Richter, L., Meier, H., Yadhukumar, et al. (2004) ARB: a software environment for sequence data. Nucleic Acids Res 32: 1363-1371.

Pan, H., Zhu, K., Song, T., Yu-Zhang, K., Lefèvre, C.T., Xing, S., et al. (2008) Characterization of a homogeneous taxonomic group of marine magnetotactic cocci within a low tide zone in the China Sea. Environ Microbiol 10: 11581164.

Postec, A., Tapia, N., Bernadac, A., Joseph, M., Davidson, S., Wu, L.F., et al. (2012) Magnetotactic bacteria in microcosms originating from the French Mediterranean Coast subjected to oil industry activities. Microb Ecol 63: $1-11$.

Pruesse, E., Quast, C., Knittel, K., Fuchs, B.M., Ludwig, W., Peplies, J., and Glöckner, F.O. (2007) SILVA: a comprehensive online resource for quality checked and aligned ribosomal RNA sequence data compatible with ARB. Nucleic Acids Res 35: 7188-7196.

Pruesse, E., Peplies, J., and Glöckner, F.O. (2012) SINA: Accurate high-throughput multiple sequence alignment of ribosomal RNA genes. Bioinformatics 28: 1823-1829.

Richter, M., Kube, M., Bazylinski, D.A., Lombardot, T., Glöckner, F.O., Reinhardt, R., and Schüler, D. (2007) Comparative genome analysis of four magnetotactic bacteria reveals a complex set of group-specific genes implicated in magnetosome biomineralization and function. $J$ Bacteriol 189: 4899-4910.

Rodrigue, S., Malmstrom, R.R., Berlin, A.M., Birren, B.W., Henn, M.R., and Chisholm, S.W. (2009) Whole genome amplification and de novo assembly of single bacterial cells. PLOS ONE 4: e6864.

Schleifer, K.H., Schüler, D., Spring, S., Weizenegger, M., Amann, R., Ludwig, W., and Köhler, M. (1991) The genus Magnetospirillum gen. nov., description of Magnetospirillum gryphiswaldense sp. nov. and transfer of Aquaspirillum magnetotacticum to Magnetospirillum magnetotacticum comb. nov. Syst Appl Microbiol 14: 379-385.

Schübbe, S., Kube, M., Scheffel, A., Wawer, C., Heyen, U., Meyerdierks, A., et al. (2003) Characterization of a spontaneous nonmagnetic mutant of Magnetospirillum gryphiswaldense reveals a large deletion comprising a putative magnetosome island. J Bacteriol 185: 57795790.

Schüler, D. (1994) Isolierung und Charakterisierung magnetischer Bakterien - Untersuchungen zur Magnetitbiomineralisation in Magnetospirillum gryphiswaldense, pp. 1-125. München: TU München.

Schüler, D., and Bazylinski, D.A. (2007) Techniques for studying uncultured and cultured magnetotactic bacteria. In Manual of Environmental Microbiology. Hurst, C.J., Crawford, R.L., Garland, J.L., Lipson, D.A., Mills, A.L., and Setzenbach, L.D. (eds). Washington DC, USA: ASM Press, pp. 1129-1138.

Silva, K.T., Abreu, F., Keim, C.N., Farina, M., and Lins, U. (2008) Ultrastructure and cytochemistry of lipid granules in the many-celled magnetotactic prokaryote, 'Candidatus Magnetoglobus multicellularis'. Micron 39: 13871392.

Simon, C., and Daniel, R. (2010) Construction of small-insert and large-insert metagenomic libraries. Methods $\mathrm{Mol}$ Biol 668: 39-50.

Spring, S., and Schleifer, K.H. (1995) Diversity of magnetotactic bacteria. Syst Appl Microbiol 18: 147-153.

Spring, S., Amann, R., Ludwig, W., Schleifer, K.H., van Gemerden, H., and Petersen, N. (1993) Dominating role of an unusual magnetotactic bacterium in the microaerobic zone of a freshwater sediment. Appl Environ Microbiol 59: 2397-2403.

Spring, S., Amann, R., Ludwig, W., Schleifer, K.H., Schüler, D., Poralla, K., and Petersen, N. (1995) Phylogenetic analysis of uncultured magnetotactic bacteria from alphasubclass of Proteobacteria. Syst Appl Microbiol 17: 501508.

Ullrich, S., Kube, M., Schübbe, S., Reinhardt, R., and Schüler, D. (2005) A hypervariable 130-kilobase genomic region of Magnetospirillum gryphiswaldense comprises a magnetosome island which undergoes frequent rearrangements during stationary growth. $J$ Bacteriol 187: 71767184.

Vali, H., and Kirschvink, J.L. (1991) Observations of magnetosome organization, surface structure, and iron biomineralization of undescribed magnetic bacteria. In Iron Biominerals. Frankel, R.B., and Blakemore, R.P. (eds). New York: Plenum Press, pp. 97-116.

Wenter, R., Wanner, G., Schüler, D., and Overmann, J. (2009) Ultrastructure, tactic behaviour and potential for sulfate reduction of a novel multicellular magnetotactic prokaryote from North Sea sediments. Environ Microbiol 11: 1493-1505.

Wolfe, R.S., Thauer, R.K., and Pfennig, N. (1987) A 'capillary racetrack' method for isolation of magnetotactic bacteria. FEMS Microbiol Ecol 45: 31-35.

Woyke, T., Tighe, D., Mavromatis, K., Clum, A., Copeland, A., Schackwitz, W., et al. (2010) One bacterial cell, one complete genome. PLOS ONE 5: e10314.

\section{Supporting information}

Additional Supporting Information may be found in the online version of this article: 
Fig. S1. Schematic of experimental set-up of the combined approach to recover diversity from magnetic collections and genomic analysis of single cells. After a magnetic enrichment from an environmental sample $(A)$ a selective enriched collection of MTB was obtained (B). Using universal eubacterial primers almost full-length 16S rRNA genes were amplified and subcloned for sequencing (C). Every MTB morphotype was selected by single cell sorting applying micromanipulation under microscopic control (D). Genomic
DNA of selected cells were amplified using the viral \$29 DNA-polymerase by multiple displacement amplification (MDA). Amplified DNA served as template for 16S rRNA PCR allowing phylogenetic analysis of selected morphotypes (E). For genetic analysis of microsorted CS-05 cells genomic DNA was amplified a second time by the MDA, enzymatically debranched, checked for contaminations and subcloned for analysis (F). 